\title{
EDITORIAL: MAKING HISTORY
}

\author{
Christopher Fox
}

The idea of journalism as 'the first rough draft of history', often attributed to Philip L. Graham of the Washington Post, is one that reaches back at least 100 years. Yet it probably overstates the provisional nature of that first draft: so many histories do little more than recycle, the passage of time polishing away the roughness, leaving us with something as shiny as a fact, but not quite true. As a journal, TEMPO is in the first draft business, but in this particular issue a recurrent theme is the questioning of the historical and historiographical process.

The music that currently calls itself 'classical' has always been generous to historians, leaving a helpful paper-trail of scores, programme books and concert reviews behind, and more recently the advent of sound recording has enabled other forms of musicmaking to leave an audible, collectable trace. All too often, however, archival material is ignored in favour of another telling of the story provided in that first draft. Ian Helliwell's research into some of the forgotten figures in early British electronic music shows how the conventional history of electronic music in the 1950 s and 60 s - a tale of groups of composers clustered around large institutions - became a common sense orthodoxy. Of course, that's how the story should go because, after all, electronic music requires expensive equipment if it's going to be of any worth. But, as Helliwell argues, what if that were not the case? What about a music made by people who owned their own tape recorder, understood circuit diagrams and could assemble home studios of their own? How do we account for a music that is stored in people's attics rather than in humidity-controlled vaults?

If the history of electronic music has, until now, mostly been written around large institutions, then it might also be useful to think about other ways in which music history has been centralised. In the UK, those of us who are not born and bred Londoners tend to be suspicious of a hegemonic metropolitan musical culture, but in Canada the situation is much more complicated, complicated by the vastness of the land and its distinctly different cultural zones. In TEMPO 280 Anna Höstman interviewed Linda Catlin Smith, a Toronto-based composer whose music is at last beginning to become much better known, with the recent releases of recordings on the Another Timbre label an important step towards wider recognition. In this issue Anna introduces Christopher Butterfield, a major figure in Victoria, British Columbia, who is also quite well-known in the rest of Canada. Why is his provocatively enigmatic music not much better known? Is it because of his typically Canadian modesty, or because Victoria is a long way away from ... where? somewhere bigger? somewhere more economically significant?

We are now nearly 30 years past 'the end of history' and struggling with the reality of a world in which truth is for some a malleable convenience, for others an ideological weapon with which to justify the most terrible atrocities. In such a world we need history more than ever: a history that is based on real things that actually 
happen, wherever and to whomever that might be. Because of its ephemerality - scores and recordings are traces of activity, not the activity itself - music is an ideal testing ground for such a history, nowhere more so than in the recent work of Éliane Radigue. As Luke Nickel explained in his article on her music in TEMPO 275, Radigue now creates her work in collaboration with her performers, developing it out of their practice and using their memories as the only repository in which the work is kept. In this issue, Cat Hope and Carol Robinson describe how they have taken this process to the next stage, with Robinson, rather than Radigue herself, becoming the agent by which a Radigue work is recreated.

Such a history is both personal - Robinson is not Radigue - and challenging too - if Robinson does not truly represent what she learned from Radigue then the end result is a fake. Above all, it's a history that depends on truth and, in a world where one of the most powerful men issues 140-character untruths in the small hours of most mornings, that has never been more important. Jakob Ullmann's music exemplifies this too, understandably when one remembers that he grew up in the German Democratic Republic, a state in which nothing was as it seemed. Oliver Thurley wrote about Ullmann in TEMPO 274 and this time focuses on a single epic work, voice, books and FIRE, a work which is both a history and a test of what history can be, dedicated to those 'have been upholders and witnesses of ... forgotten and dismissed traditions'. As with the articles by Nomi Epstein and Daniel Wilson in TEMPO 281 this is part of a study on music and fragility, curated by Martin Iddon and Daniel Wilson, and once again I would like to thank them for allowing TEMPO to publish these articles. 